\title{
Prognosis of Hypothermic Patients Undergoing ECLS Rewarming-Do Alterations in Biochemical Parameters Matter?
}

\author{
Hubert Hymczak ${ }^{1,2}{ }^{\text {, Paweł Podsiadło }}{ }^{3} \oplus$, Sylweriusz Kosiński ${ }^{4}$, Mathieu Pasquier ${ }^{5} \oplus$, Konrad Mendrala ${ }^{6}(\mathbb{D}$, \\ Damian Hudziak ${ }^{7}$, Radosław Gocol ${ }^{7}$, Dariusz Plicner ${ }^{8, * 10}$ and Tomasz Darocha ${ }^{6}$
}

check for

updates

Citation: Hymczak, H.; Podsiadło, P. Kosiński, S.; Pasquier, M.; Mendrala,

K.; Hudziak, D.; Gocoł, R.; Plicner, D.; Darocha, T. Prognosis of

Hypothermic Patients Undergoing ECLS Rewarming-Do Alterations in Biochemical Parameters Matter? Int. J Environ. Res. Public Health 2021, 18 9764. https://doi.org/10.3390/ ijerph18189764

Academic Editor: Paul B. Tchounwou

Received: 30 July 2021

Accepted: 13 September 2021

Published: 16 September 2021

Publisher's Note: MDPI stays neutral with regard to jurisdictional claims in published maps and institutional affiliations.

Copyright: (c) 2021 by the authors Licensee MDPI, Basel, Switzerland. This article is an open access article distributed under the terms and conditions of the Creative Commons Attribution (CC BY) license (https:// creativecommons.org/licenses/by/ $4.0 /)$
1 Department of Anesthesiology and Intensive Care, John Paul II Hospital, 31-202 Krakow, Poland; hymczak@op.pl

2 Faculty of Medicine and Health Sciences, Andrzej Frycz Modrzewski Krakow University, 30-705 Krakow, Poland

3 Institute of Medical Sciences, Jan Kochanowski University, 25-369 Kielce, Poland; p.podsiadlo.01@gmail.com

4 Faculty of Health Sciences, Jagiellonian University Medical College, 31-008 Krakow, Poland; kosa@mp.pl

5 Emergency Department, Lausanne University Hospital, University of Lausanne, 1015 Lausanne, Switzerland; mathieu.pasquier@chuv.ch

6 Department of Anaesthesiology and Intensive Care, Medical University of Silesia, 40-055 Katowice, Poland; k.mendrala@gmail.com (K.M.); tomekdarocha@wp.pl (T.D.)

7 Department of Cardiac Surgery, Medical University of Silesia, 40-055 Katowice, Poland; damhud@gmail.com (D.H.); gocot@poczta.onet.pl (R.G.)

8 Unit of Experimental Cardiology and Cardiac Surgery, Faculty of Medicine and Health Sciences, Andrzej Frycz Modrzewski Krakow University, 30-705 Krakow, Poland

* Correspondence: plicner.dariusz@gmail.com

Abstract: Background: While ECLS is a highly invasive procedure, the identification of patients with a potentially good prognosis is of high importance. The aim of this study was to analyse changes in the acid-base balance parameters and lactate kinetics during the early stages of ECLS rewarming to determine predictors of clinical outcome. Methods: This single-centre retrospective study was conducted at the Severe Hypothermia Treatment Centre at John Paul II Hospital in Krakow, Poland. Patients $\geq 18$ years old who had a core temperature $(\mathrm{Tc})<30{ }^{\circ} \mathrm{C}$ and were rewarmed with ECLS between December 2013 and August 2018 were included. Acid-base balance parameters were measured at ECLS implantation, at Tc $30^{\circ} \mathrm{C}$, and at 2 and $4 \mathrm{~h}$ after Tc $30^{\circ} \mathrm{C}$. The alteration in blood lactate kinetics was calculated as the percent change in serum lactate concentration relative to the baseline. Results: We included 50 patients, of which 36 (72\%) were in cardiac arrest. The mean age was $56 \pm 15$ years old, and the mean Tc was $24.5 \pm 12.6^{\circ} \mathrm{C}$. Twenty-one patients $(42 \%)$ died. Lactate concentrations in the survivors group were significantly lower than in the non-survivors at all time points. In the survivors group, the mean lactate concentration decreased $-2.42 \pm 4.49 \mathrm{mmol} / \mathrm{L}$ from time of ECLS implantation until $4 \mathrm{~h}$ after reaching Tc $30^{\circ} \mathrm{C}$, while in the non-survivors' group ( $p=0.024)$, it increased $1.44 \pm 6.41 \mathrm{mmol} / \mathrm{L}$. Conclusions: Our results indicate that high lactate concentration is associated with a poor prognosis for hypothermic patients undergoing ECLS rewarming. A decreased value of lactate kinetics at $4 \mathrm{~h}$ after reaching $30^{\circ} \mathrm{C}$ is also associated with a poor prognosis.

Keywords: ECLS; accidental hypothermia; lactate; lactate kinetics; rewarming

\section{Introduction}

Accidental hypothermia is a specific cause of cardiac arrest (CA) of which a survival rate in witnessed CA is about $56 \%$ and is approximately $27 \%$ in unwitnessed CA, mostly with good neurologic outcome [1,2]. Currently, extracorporeal life support (ECLS) rewarming is the method of choice in the treatment of out-of-hospital cardiac arrest patients (OHCA) with severe accidental hypothermia [3]. However, ECLS is a highly invasive procedure, fraught with the risk of serious complications and is not broadly accessible [4]. 
Therefore, the identification of patients with a potentially good prognosis is of high importance. For years, the serum potassium concentration has been used to indicate patients who have potential for survival [5]. Recently, the "HOPE score" was developed to predict the outcome among OHCA patients with hypothermia if ECLS rewarming is applied [1]. However, this calculator includes data from the prehospital period, and its main value is to help clinicians decide whether to continue resuscitation efforts with ECLS rewarming. Apart from CA patients, patients with cardiac instability caused by severe accidental hypothermia can also be successfully rewarmed with ECLS [3]. To the best of our knowledge, no criteria have yet been developed to estimate the chances of survival of severely hypothermic patients, with or without cardiac arrest, after the initialization of extracorporeal treatment. It would be of great value to find means to identify the high-risk patients earlier in whom the therapy should be intensified or modified. Recent studies by Darocha et al. and Podsiadlo et al. highlight the important role of the acid-base balance parameters and the lactate concentration in the prognosis of victims of accidental hypothermia rewarmed with ECLS [6,7]. Therefore, it seems likely that observing the changes in these parameters over time can help predict the patients' outcome. The aim of this study was to analyse the changes in the acid-base balance parameters and lactate kinetics during the early stages of ECLS rewarming to indicate the predictors of clinical outcome.

\section{Materials and Methods}

This single-centre retrospective study was conducted at the Severe Hypothermia Treatment Centre (SHTC) at John Paul II Hospital in Krakow, Poland. Data were collected from available medical records in paper and electronic form. The primary outcome was the survival to discharge from the intensive care unit. The individual variables and treatment outcomes were analysed by the comparison of the surviving patient group to the patients that died. Study approval was obtained from the Bioethics Committee of the Jagiellonian University Medical College, Krakow, Poland (no. 1072.6120.344.2018).

\subsection{Inclusion and Exclusion Criteria}

Patients with accidental hypothermia selected for this study were over the age of 18 and referred to SHTC by telephone, by emergency medical services (EMS), as well as by the hospital emergency department team between December 2013 and August 2018. Based on their medical history, only patients subsequently qualified for extracorporeal therapy were included in this study.

The exclusion criteria were as follows: core temperature $(\mathrm{Tc}) \geq 30^{\circ} \mathrm{C}$, veno-arterial Extra Corporeal Membrane Oxygenation (v-a ECMO) implantation outside SHTC, disqualification from v-a ECMO therapy, and initiation of renal replacement therapy less than $12 \mathrm{~h}$ after v-a ECMO implantation.

Severe hypothermia was confirmed by measuring the oesophageal temperature at hospital admission. Haemodynamic instability was diagnosed on the basis of at least one of the following criteria: systolic blood pressure $<90 \mathrm{mmHg}$ and/or ventricular arrhythmia.

\subsection{Data Collection}

The following patient information was collected: age, gender, Tc, heart rate, blood pressure, and in case of sudden CA, the time of resuscitation to initiation of $\mathrm{v}-\mathrm{a}$ ECMO; circumstances of hypothermia, rate of rewarming, duration of ECLS, duration of mechanical ventilation, fluid load and diuresis in the first $24 \mathrm{~h}$, use of catecholamines, duration of Intensive Care Unit (ICU) stay, and cerebral performance category scale (CPC), which was assessed at discharge from the ICU.

Biochemical parameters were measured at the following time points: $\mathrm{T} 1$ - at ECMO implantation; T2-obtained Tc $30{ }^{\circ} \mathrm{C}$; T3-2 h after Tc $30^{\circ} \mathrm{C}$; and T4-4 h after Tc $30^{\circ} \mathrm{C}$. Alpha-stat arterial blood gas analysis $\left(\mathrm{pH}, \mathrm{PaCO}_{2}, \mathrm{PaO}_{2}\right.$, and concentrations of $\mathrm{HCO}_{3}, \mathrm{BE}$, potassium, haemoglobin, glucose, and lactate) was performed at all time points. The value of blood lactate kinetics was calculated as the percent change in serum lactate concentration 
at time points $\mathrm{T} 2, \mathrm{~T} 3$, and $\mathrm{T} 4$ relative to the baseline lactate concentration at time point $\mathrm{T} 1$ and to the relative preceding time point, according to the following formula [8]:

$$
\text { Lactate kinetics at time point }(\%)=\frac{\text { initial LAC }- \text { subsequent LAC }}{\text { initial LAC } \times 100}
$$

A positive value of lactate kinetics represents a decrease in serum lactate concentration, while a negative lactate kinetics indicates an increase in serum lactate concentration at consecutive time points. Tests were performed in a Randox International Quality Assessment Scheme (RIQAS) certified laboratory. Samples were routinely analysed with the Cobas 6000 (Roche Diagnostic GmbH, Manheim, Germany) and the ABL835 FLEX (Radiometer Medical ApS, Brønshøj, Copenhagen, Denmark) analysers.

\subsection{Clinical Procedure}

In all cases, v-a ECMO therapy was initially performed using a Rotaflow Console REF 706037 (Maquet, Rastatt, Germany) with a Medos Deltastream HC heat exchanger (Inspiration Healthcare Group, Cravley, UK) and then continued with the heat unit HU 35 (Maquet, Rastatt, Germany) and a permanent life support set oxygenator (Maquet, Rastatt, Germany) that used an HLS Cannulae with BIOLINE Coating (Maquet, Rastatt, Germany). Implantation via peripheral access was performed through insertion of a 17-21 F size arterial cannula in the right or left femoral artery and a 22-24 F size venous cannula through the right or left femoral vein. The rewarming rate was individually determined according to the patients' clinical needs. Patients were transferred to the ICU once their heart rate stabilised and a body temperature of $\geq 32{ }^{\circ} \mathrm{C}$ was achieved.

$\mathrm{V}$-a ECMO support was removed when normothermia was achieved and the circulatory system was stabilised after at least six hours of therapy. In cases of lower limb ischaemic complications or massive bleeding at the implantation site, the support was removed before six hours. If normothermia was achieved with haemodynamic instability, persistent asystole, and inability to maintain v-a ECMO output, death was pronounced. Catecholamines (epinephrine, norepinephrine, dobutamine) were needed for all patients. Red blood cell concentrate was transfused to achieve a haemoglobin concentration $\geq 10 \mathrm{~g} / \mathrm{dL}$ as required.

\subsection{Statistical Analysis}

We compared the values of biochemical parameters between the survivors and nonsurvivors groups at each time point. We also calculated the differences in these values between consecutive time points in each group and then compared these trends between groups. The quantitative variables are presented as the mean with standard deviation (SD) or the median (M) and the lower (q1) and upper (q3) quartiles depending on the distribution of the variable. Normal distribution was investigated using the Shapiro-Wilk test. The distribution of qualitative variables is described as the absolute and relative frequencies. The relationship between two qualitative features was analysed with the chi-square test. Significance of the quantitative traits between the two groups was analysed using Student's $t$-test (the distribution follows the normal distribution) or Mann-Whitney $\mathrm{U}$ test (the distribution deviates from the normal distribution). The repeated-measures ANOVA test was used to compare the trends of biochemical parameters at consecutive time points between the groups. Multivariate logistic regression was then used to identify predictors of survival. The results are presented as odds ratio (OR) and a 95\% confidence interval $(95 \% \mathrm{CI})$. Additionally, a moderation analysis was performed to investigate if CA occurrence influenced the relationship between survival and the studied parameters. Since no significant interaction was observed, patients with preserved circulation and those in cardiac arrest were not analysed separately. Analyses were performed using IBM SPSS Statistics for Windows, version 25 (IBM Corp., Armonk, NY, USA) and Statistica 12.0 (Statsoft, Tulsa, OK, USA). A level of $\alpha=0.05$ for two-tailed tests was used to indicate significance. 


\section{Results}

Fifty-two patients met the eligibility criteria. Two patients were excluded from the study because the v-a ECMO was not implanted at the SHTC, and a different treatment regimen was used in conjunction with incomplete medical and laboratory data. The remaining 50 patients (mean age of $56 \pm 14.6$ years) were included. The youngest patient was 19 years old and the oldest was 84 . Thirty-nine of the patients were men (78\%). The mean Tc on admission was $24.5^{\circ} \mathrm{C}\left(\mathrm{SD} 2.6\right.$; range $\left.16.9-29^{\circ} \mathrm{C}\right)$. This study included two drowning victims $(4 \%)$ and one patient $(2 \%)$ buried in an avalanche (extricated with preserved circulation). The remaining patients suffered from exposure to cold air. However, specific data regarding these events and the detailed patient characteristics are incomplete and not suitable for analysis. Thirty-six patients $(72 \%)$ were in CA at the time of cannulation, and fourteen $(28 \%)$ had preserved circulation. Among the patients who experienced CA, in 24 cases $(66.7 \%)$ the initial heart rhythm was ventricular fibrillation (VF), in 11 cases asystole $(30.5 \%)$, and pulseless electrical activity (PEA) occurred in one case $(2.8 \%)$. In seven cases (19.4\%) cardiac arrest occurred before the victim was found. The median resuscitation time was $140 \mathrm{~min}$ (IQR 102-202.5). The mean systolic pressure among patients with preserved circulation was $67.14 \pm 10.69 \mathrm{mmHg}$. The median duration of v-a ECMO therapy was $21.5 \mathrm{~h}$ (IQR 8.33-33). The median rewarming rate was $1.8^{\circ} \mathrm{C} / \mathrm{h}$ (range: $0.4-6^{\circ} \mathrm{C} / \mathrm{h}$ ).

Twenty-one study participants $(42 \%)$ died, and of those, four died before the T4 time point. Men accounted for $71 \%$ of the deceased patients. Twenty-seven patients who survived (93\%) were scored with CPC-1 and two (7\%) with CPC-2. The measured parameters at admission between the survivors and those that died are summarised in Table 1.

Table 1. Patients' characteristics on admission.

\begin{tabular}{|c|c|c|c|c|c|}
\hline Overall $(n=50)$ & $\begin{array}{c}\text { Survival at ICU } \\
\text { Discharge }(n=29)\end{array}$ & & $\begin{array}{l}\text { Death } \\
(n=21)\end{array}$ & & $p$ \\
\hline Age, Mean & 55.30 & \pm 12.96 & 56.50 & \pm 16.87 & 0.783 \\
\hline Men, $n(\%)$ & 24.00 & $82.8 \%$ & 15.00 & $71.4 \%$ & 0.336 \\
\hline $\mathrm{pH}$ & 6.99 & \pm 0.17 & 6.89 & \pm 0.21 & 0.067 \\
\hline $\mathrm{pCO}_{2}(\mathrm{mmHg})$ & 51.50 & \pm 20.03 & 56.50 & \pm 24.24 & 0.424 \\
\hline $\mathrm{pO}_{2}(\mathrm{mmHg})$ & 92.00 & $(53.8-317.0)$ & 73.70 & $(53.9-130)$ & 0.265 \\
\hline $\mathrm{HCO}_{3}(\mathrm{mmol} / \mathrm{L})$ & 12.00 & \pm 4.37 & 10.50 & \pm 4.63 & 0.258 \\
\hline $\mathrm{BE}(\mathrm{mmol} / \mathrm{L})$ & -19.30 & \pm 6.29 & -23.20 & \pm 7.4 & 0.054 \\
\hline $\mathrm{K}+(\mathrm{mmol} / \mathrm{L})$ & 3.90 & \pm 1.21 & 5.00 & \pm 1.61 & $0.008 *$ \\
\hline Haemoglobin (g/dL) & 12.30 & \pm 3.3 & 11.80 & \pm 3.07 & 0.566 \\
\hline Glucose (mmol/L) & 8.10 & $(4.5-11.5)$ & 6.30 & $(4.1-10.2)$ & 0.520 \\
\hline Lactate $(\mathrm{mmol} / \mathrm{L})$ & 9.80 & \pm 4.96 & 13.20 & \pm 5.73 & 0.028 * \\
\hline Tc $\left({ }^{\circ} \mathrm{C}\right)$ & 23.90 & \pm 2.64 & 25.20 & \pm 2.41 & 0.090 \\
\hline CA & 19 & $66.5 \%$ & 17 & $81.0 \%$ & 0.230 \\
\hline $\begin{array}{c}\text { Time from CA Onset } \\
\text { to v-a ECMO } \\
\text { Implantation (min) }\end{array}$ & 144.00 & (120-195) & 120.00 & $(67.0-240)$ & 0.350 \\
\hline
\end{tabular}

Numerical values are presented in the following order: the number of patients or the mean or median values and the percentage $(\%)$ or standard deviation $( \pm)$ or lower and upper quartile (q1-q3). ICU—Intensive Care Unit, Tc - core temperature, CA—cardiac arrest, v-a ECMO—veno-arterial Extra Corporeal Membrane Oxygenation.

\subsection{Changes of Concentrations in the Biochemical Parameters}

The blood $\mathrm{pH}, \mathrm{PaCO}_{2}, \mathrm{PaO}_{2}, \mathrm{HCO}_{3}, \mathrm{BE}$, and $\mathrm{Hgb}$ values changed significantly between subsequent time points in each group, although there were no significant differences in these values between the survivors and non-survivors groups (Figure 1). 

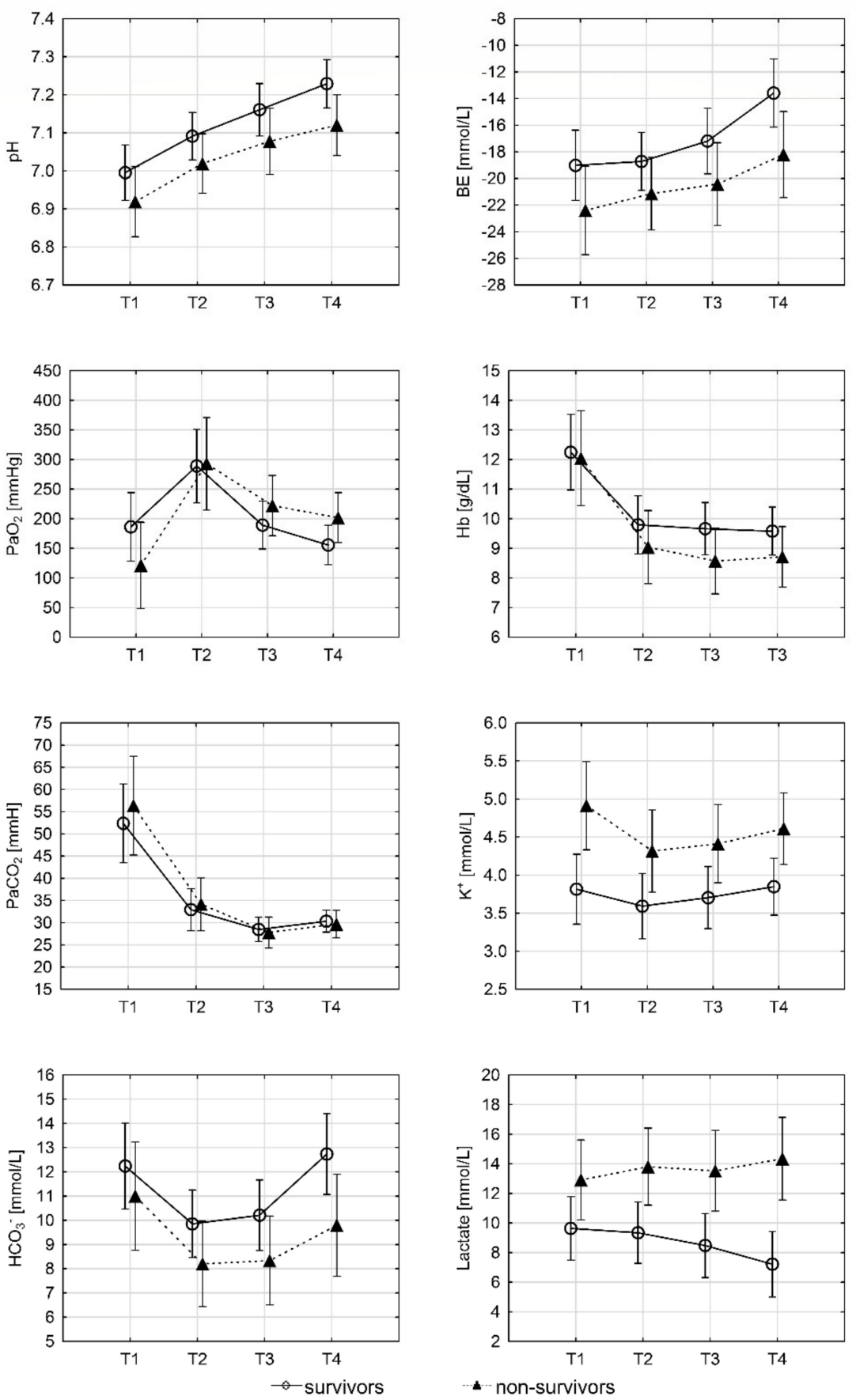

Figure 1. The mean values of blood $\mathrm{pH}, \mathrm{PaCO}_{2}, \mathrm{PaO}_{2}, \mathrm{HCO}_{3}, \mathrm{BE}$, and $\mathrm{Hgb}$ values are plotted at different time points. The bars represent a $95 \%$ confidence interval. T1-time at ECMO implantation, T2 - time obtained Tc $30{ }^{\circ} \mathrm{C}$, T3-2 $\mathrm{h}$ after Tc $30^{\circ} \mathrm{C}$, and T4-4 h after Tc $30^{\circ} \mathrm{C}$.

The survivors group blood $\mathrm{pH}$ was significantly higher than that of the non-survivors group at time point $\mathrm{T} 4(7.23 \pm 0.16$ vs. $7.12 \pm 0.17 ; p=0.037)$. There was no statistically significant difference in $\mathrm{PaO}_{2}$ and $\mathrm{PaCO}_{2}$ values between the groups at any time point. A significantly higher $\mathrm{HCO}_{3}$ concentration was observed in the survivors group at time point T4 (12.70 \pm 4.42 vs. $9.80 \pm 4.07 ; p=0.03)$. The survivors also had a significantly higher $\mathrm{BE}$ than non-survivors at time point $\mathrm{T} 4(-13.60 \pm 6.55$ vs. $-18.20 \pm 6.69 ; p=0.029)$. The serum potassium concentrations were significantly lower in the survivors group at all time points. However, these concentrations did not change significantly in the consecutive time points. 
The lactate concentrations in the survivors group were significantly lower at all time points than in the non-survivors. There was also a statistically significant difference in the lactate decrease between time points $\mathrm{T} 4$ and $\mathrm{T} 1$ in the survivors group compared to the non-survivors. A significant decrease in the mean lactate concentrations occurred among the survivors, while no significant change was observed in the non-survivors. A significant difference between groups in lactate kinetics was observed for T4-T1 and T4-T3 values. The difference in lactate kinetics value for the other time points did not reach statistical significance (Table 2). The highest lactate concentration registered in a survivor was $21 \mathrm{mmol} / \mathrm{L}$, and which was measured at the T1 time point in a patient with preserved spontaneous circulation.

Table 2. Changes in lactate concentrations and kinetics in arterial blood gas from T1 to T4 time points.

\begin{tabular}{cccccc}
\hline Concentration & Survival & \multicolumn{5}{c}{ Death } & $p$ \\
\hline T1 $(n=50)$ & 9.80 & \pm 4.96 & 13.20 & \pm 5.73 & $0.028^{*}$ \\
T2 $(n=49)$ & 9.40 & \pm 4.58 & 13.90 & \pm 5.94 & $0.004^{*}$ \\
T3 $(n=48)$ & 8.50 & \pm 4.65 & 13.30 & \pm 6.50 & $0.005^{*}$ \\
T4 $(n=44)$ & 7.20 & \pm 4.83 & 14.30 & \pm 6.90 & $<0.001^{*}$ \\
Difference in Concentration & & & & \\
T2-T1 $(n=49)$ & -0.36 & \pm 2.06 & 0.73 & \pm 3.82 & 0.204 \\
T3-T1 $(n=48)$ & -1.29 & \pm 3.46 & 0.44 & \pm 4.16 & 0.126 \\
T4-T1 $(n=44)$ & -2.42 & \pm 4.49 & 1.44 & \pm 6.41 & $0.024^{*}$ \\
Lactate kinetics & & & & & \\
T2/T1 $(n=49)$ & 0.78 & $(-11.3-15.5)$ & 1.08 & $(-11.5-10.1)$ & 0.490 \\
T3/T1 $(n=48)$ & 5.90 & $(-10.5-37.1)$ & 1.70 & $(-26.1-21.1)$ & 0.320 \\
T4/T1 $(n=44)$ & 21.20 & $(-14.1-56.8)$ & -2.60 & $(-16.0-13.5)$ & $0.048^{*}$ \\
T3/T2 $(n=48)$ & 0.00 & $(-8.8-33.1)$ & -1.77 & $(-14.3-19.7)$ & 0.310 \\
T4/T3 $(n=44)$ & 24.00 & $(-4.5-40.0)$ & 0.00 & $(-8.1-8.1)$ & $0.008^{*}$ \\
${ }^{*} p<0.05$. & & &
\end{tabular}

A comparison of clinical parameters between survivors and those who died is shown in Table 3. All patients required catecholamine supply early on during v-a ECMO therapy. The rewarming rate ranged from $0.4-6{ }^{\circ} \mathrm{C} / \mathrm{h}$ and did not differ significantly between groups.

Table 3. Distribution of the analysed clinical parameters in the survivors and those that died.

\begin{tabular}{|c|c|c|c|c|c|}
\hline Variable & $\begin{array}{c}\text { Survival } \\
(n=29)\end{array}$ & & $\begin{array}{c}\text { Death } \\
(n=21)\end{array}$ & & $p$ \\
\hline $\begin{array}{c}\mathrm{NaHCO}_{3} 8.4 \% \text { Therapy } \\
0-24 \mathrm{~h}(\mathrm{~mL})\end{array}$ & 80 & $(40-80)$ & 140 & $(100-200)$ & 0.070 \\
\hline \multicolumn{6}{|l|}{ Transfusions of RCC (n) } \\
\hline$\leq 4$ units & 18 & $(62)$ & 10 & $(48)$ & \multirow{2}{*}{0.310} \\
\hline$>4$ units & 11 & (38) & 11 & (52) & \\
\hline Rewarming Rate $\left({ }^{\circ} \mathrm{C} / \mathrm{h}\right)$ & 1.78 & $(1.35-2.90)$ & 2.07 & $(1.55-2.60)$ & 0.350 \\
\hline $\begin{array}{c}\text { Duration of v-a ECMO } \\
\text { Therapy }(\mathrm{h})\end{array}$ & 23 & $(21-34)$ & 9 & $(6-21)$ & $<0.001 *$ \\
\hline $\begin{array}{c}\text { Length of ICU } \\
\text { Hospitalisation (Days) }\end{array}$ & 13 & $(8-22)$ & 1 & $(1-3)$ & $<0.001$ * \\
\hline Mechanical Ventilation (h) & 164 & (74-298) & 29 & $(9-51)$ & $<0.001 *$ \\
\hline Diuresis 0-24 h (mL) & 3300.00 & $(2400-4300)$ & 650.00 & $(50-1050)$ & $<0.001$ * \\
\hline Fluid therapy $0-24 \mathrm{~h}(\mathrm{~mL})$ & $10,889.70$ & $(3338.56)$ & 9431.00 & $(3881.64)$ & 0.160 \\
\hline
\end{tabular}

Lactate concentration is expressed in ( $\mathrm{mmol} / \mathrm{L})$ as a mean and standard deviation $( \pm)$. Lactate kinetics is expressed in $\%$ as median and lower and upper quartile (q1-q3). T1-time at ECMO implantation, T2 - time obtained Tc $30^{\circ} \mathrm{C}$, T3-2 h after Tc $30^{\circ} \mathrm{C}$, and T4- $4 \mathrm{~h}$ after Tc $30^{\circ} \mathrm{C}$. 
Numerical values are presented in the following order: median, lower and upper quartiles (q1-q3) or mean value, standard deviation or numerical value, percentage. NaHCO3sodium bicarbonate, RCC—Red cell concentrate, v- a ECMO—veno-arterial Extra Corporeal Membrane Oxygenation, ICU—Intensive Care Unit.

\subsection{Predictors of Survival}

The strongest predictor associated with survival was observed for lactate concentration at T4 point. This was determined with a receiver operating characteristic curve (ROC) analysis for the occurrence of death in relation to the lactate concentration at time point T4 and is presented in Figure 2. We found that a lactate concentration above $12.55 \mathrm{mmol} / \mathrm{L}$ at the T4 time point increases the risk of death.

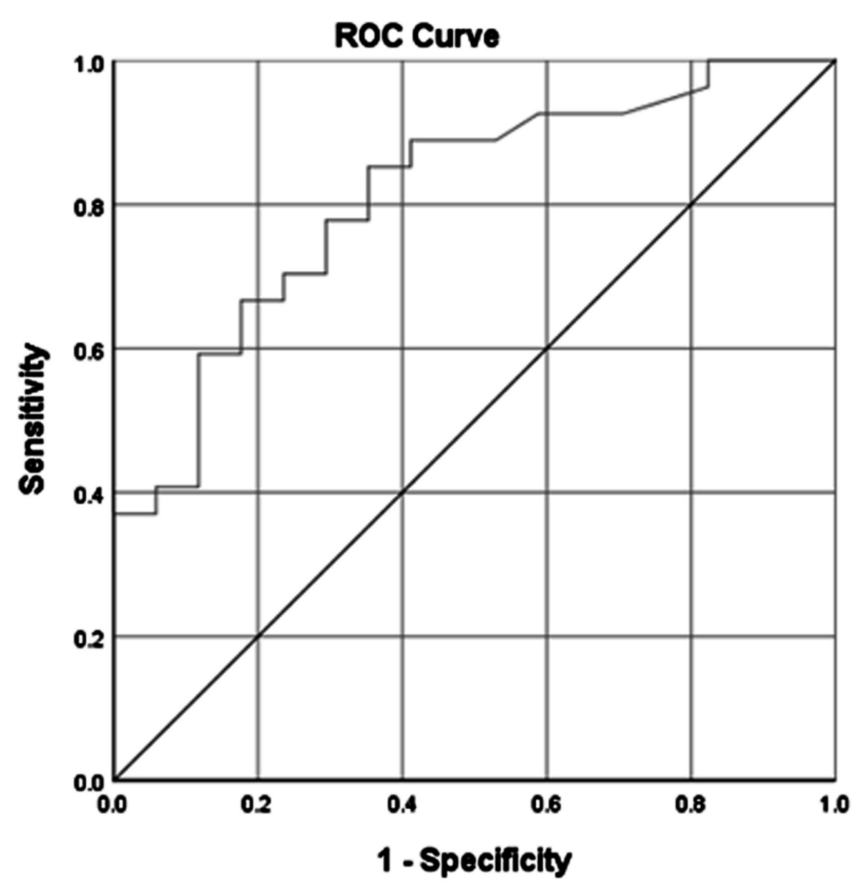

Figure 2. Receiver operating characteristic curve (ROC) analysis for the occurrence of death in relation to the lactate concentration at time point T4. AUROC (area under the receiver operating characteristic curve) - 0.812. Standard error-0.065. $p<0.001 .95 \% \mathrm{CI}-0.684-0.939$. Cut-off point $(95 \%$ CI $)>12.55$. Sensitivity (\%) of cut-off value-85. Specificity (\%) of cut-off value- 65 .

In the survival analysis with logistic regression, the model with the highest predictive value included: age, gender, $\mathrm{CA}$ occurrence, $\mathrm{Tc}$, rewarming rate, and lactate concentration at the analysed time points (Table 4). In this set of data, the patients' gender and lactate concentrations appeared to be independently associated with survival. The area under the ROC curve of this model was 0.911 (95\% CI 0.829-0.993). A 1-mmol/L higher lactate concentration at the T1 time point was associated with a $15 \%$ reduced chance of survival $(\mathrm{OR}=0.85,95 \% \mathrm{CI}=(0.735-0.986))$. In contrast, a $1-\mathrm{mmol} / \mathrm{L}$ higher lactate concentration at the T4 time point was associated with a $36 \%$ reduced chance of survival $(\mathrm{OR}=0.640,95 \% \mathrm{CI}$ $0.468-0.875)$. A similar predictive value was found for the model considering differences in lactate concentrations at $\mathrm{T} 4$ and $\mathrm{T} 1$ instead of absolute serum concentration ( $\mathrm{AUC}=0.906$ ).

Data presented as odds ratio (OR), $95 \%$ confidence interval (95\% CI), the area under the curve (AUC). T1 - time at ECMO implantation, T2 - time obtained Tc $30^{\circ} \mathrm{C}, \mathrm{T} 3-2 \mathrm{~h}$ after Tc $30^{\circ} \mathrm{C}$, and $\mathrm{T} 4-4 \mathrm{~h}$ after Tc $30^{\circ} \mathrm{C}$. CA—cardiac arrest. $\mathrm{T}_{\mathrm{c}}$-core temperature. 
Table 4. Relationship between survival, age, gender, CA onset, body temperature, rewarming rate, and lactate concentration from $\mathrm{T} 1$ to $\mathrm{T} 4$ time points.

\begin{tabular}{|c|c|c|c|c|c|c|c|c|c|c|c|c|}
\hline \multirow{2}{*}{ Variable } & \multicolumn{3}{|c|}{ T1 } & \multicolumn{3}{|c|}{ T2 } & \multicolumn{3}{|c|}{ T3 } & \multicolumn{3}{|c|}{$\mathrm{T} 4$} \\
\hline & OR & $95 \%$ CI & $p$ & OR & $95 \%$ CI & $p$ & OR & $95 \%$ CI & $p$ & OR & $95 \%$ CI & $p$ \\
\hline Age & 0.966 & $(0.917-1.019)$ & 0.205 & 0.954 & (0.900-1.010) & 0.104 & 0.955 & $(0.902-1.011)$ & 0.115 & 0.965 & $(0.901-1.034)$ & 0.315 \\
\hline Sex & 0.573 & $(0.124-2.642)$ & 0.475 & 0.384 & $(0.073-2.016)$ & 0.258 & 0.272 & $(0.045-1.654)$ & 0.157 & 0.043 & $(0.003-0.632)$ & $0.022 *$ \\
\hline CA (yes) & 0.213 & $(0.036-1.267)$ & 0.089 & 0.341 & $(0.057-2.061)$ & 0.241 & 0.404 & $(0.063-2.611)$ & 0.341 & 0.659 & $(0.079-5.469)$ & 0.699 \\
\hline TC & 0.754 & (0.557-1.019) & 0.066 & 0.781 & $(0.569-1.072)$ & 0.126 & 0.797 & $(0.569-1.116)$ & 0.186 & 0.711 & $(0.450-1.126)$ & 0.146 \\
\hline $\begin{array}{c}\text { Rewarming } \\
\text { Rate }\end{array}$ & 0.728 & $(0.444-1.457)$ & 0.472 & 0.728 & $(0.375-1.412)$ & 0.347 & 0.790 & $(0.403-1.548)$ & 0.492 & 0.400 & $(0.468-0.875)$ & 0.107 \\
\hline $\begin{array}{c}\text { Lactate } \\
\text { concentration } \\
\text { T1 }\end{array}$ & 0.851 & $(0.735-0.986)$ & $0.032 *$ & & & & & & & & & \\
\hline $\begin{array}{c}\text { Lactate } \\
\text { concentration } \\
\text { T2 }\end{array}$ & & & & 0.779 & $(0.649-0.934)$ & $0.007^{*}$ & & & & & & \\
\hline $\begin{array}{c}\text { Lactate } \\
\text { concentration } \\
\text { T3 } \\
\text { Lactate }\end{array}$ & & & & & & & 0.779 & $(0.653-0.929)$ & $0.005^{*}$ & & & \\
\hline $\begin{array}{c}\text { concentration } \\
\text { T4 }\end{array}$ & & & & & & & & & & 0.640 & $(0.468-0.875)$ & $0.005^{*}$ \\
\hline AUC & 0.770 & $(0.630-0.899)$ & & 0.806 & $(0.685-0.926)$ & & 0.797 & $(0.671-0.922)$ & & 0.911 & $(0.829-0.993)$ & \\
\hline
\end{tabular}

\section{Discussion}

The results of the study showed that the lactate concentration remained a significant predictor of survival at each time point analysed. The highest lactate concentration in a surviving patient was $21 \mathrm{mmol} / \mathrm{L}$. A significant difference between groups in the lactate kinetics value was observed for T4 versus $\mathrm{T} 1$ (within $4 \mathrm{~h}$ of achieving $\mathrm{Tc} 30^{\circ} \mathrm{C}$ ) and $\mathrm{T} 4$ versus T3 (within the fourth and second hours). The difference in lactate kinetics for all other time points failed to achieve statistical significance. Based on changes in serum lactate concentrations, we were able to calculate the chance of survival in hypothermic patients undergoing ECPR. The highest prognostic value was demonstrated for a lactate level within $4 \mathrm{~h}$ of achieving Tc $30^{\circ} \mathrm{C}$ and for the difference with the baseline value.

The evidence that lactate is a marker of illness severity in most situations of physiological stress is compelling. Hyperlactatemia is a characteristic feature of all shock states and the level of increase in lactate concentrations is directly related to the severity of shock and to mortality [9-11]. Lower initial serum lactate and higher $\mathrm{pH}$ were associated with a better neurologic outcome in survivors of hypothermic OHCA treated with ECPR [2,12,13]. A dynamic evaluation of serial lactate concentrations may be more informative than a single value $[14,15]$. A better prognosis was observed with decreasing lactate concentrations in most situations of hyperlactatemia in heterogeneous patient populations [11].

It should be noted that a significant number of publications describe lactate kinetics by the term "clearance"; however, as pointed out by Vincent et al., this may be misleading [11]. Plasma lactate concentration depends on changes in production and elimination, while the term clearance refers only to the elimination of a substance from the plasma per unit time. It is therefore suggested that the phrase lactate kinetics be used instead of lactate clearance. In this regard, the existing publications can be analysed with a better understanding.

The lactate clearance (more accurately, the value of lactate kinetics) rate has been suggested as a guide for clinicians in their decision to discontinue ECPR [16,17]. It therefore seems that following the lactate trend in patients may have a prognostic value and might be an indicator of ECPR's effectiveness. In a recent study, lactate clearance calculated through arterial blood gas analysis $6 \mathrm{~h}$ after ECPR proved to be one of the most important predictors of in-hospital mortality in patients treated with ECPR after cardiac arrest [15].

The effect of hyperlactatemia is governed by its severity and the clinical context. Mortality is increased by a factor of nearly three when lactic acidosis accompanies low-flow states or sepsis, and the higher the lactate level, the worse the outcome $[9,10,18]$. Although hyperlactatemia is often attributed to tissue hypoxia, it can result from other mechanisms including increased glycolysis, catecholamine-stimulated $\mathrm{Na}-\mathrm{K}$ pump activity, alterations 
in pyruvate dehydrogenase activity, and reduced lactate clearance, primarily because of liver hypoperfusion $[11,19]$.

Hypothermia-related hyperlactatemia has been observed at least since the 1980s [20]. A longer stay in a hospital of patients with lactic acidosis indicates a more severe course of hypothermia [21,22]. In a retrospective analysis from the French Alps, the median of lactate in non-survivors of hypothermic CA was almost double that of survivors [23]. Among adult $\mathrm{OHCA}$ patients with moderate-to-severe hypothermia, the predictive accuracy of $\mathrm{pH}$ of 6.9 and lactate of $13 \mathrm{mmol} / \mathrm{L}$ for 1-month survival can be useful cutoff points to rule out 1-month survival with high sensitivity [24].

The complexity of lactate metabolism during physiological stress is overwhelming, however, its complex nature makes it difficult to define what goal it should be a marker or target of [19]. In our study, we showed that a decrease in serum lactate concentration during treatment (i.e., a positive value of blood lactate kinetics) is associated with a better prognosis. However, interpreting this effect is difficult. Based on the assumption that hypothermiarelated hyperlactatemia results from hypoperfusion, optimizing systemic blood flow by means of ECPR could therefore revert ongoing hypoperfusion and improve prognosis. However, a number of elements confound the clinical use of lactate and the value of blood lactate kinetics. The best known in clinical practice is the use of catecholamines, alkalizing medications, lactate-buffered CRRT, liver dysfunction, and lung lactate production. In addition, the use of specific drugs and toxins has been associated with increased lactate levels (metformin, ethanol, steroids) [19,25].

In our study, we defined the time point $\mathrm{T} 2$ as the moment of reaching the core temperature of $30^{\circ} \mathrm{C}$, as it is considered the potential threshold of cardiovascular stabilization and the point for unaltered catecholamines action. According to the resuscitation guidelines, a core temperature of 30 is the moment of pharmacotherapy initiation, increasing the chances of successful defibrillation and return of spontaneous circulation [26-28]. These assumptions allowed us to standardize the study population in our study regarding the core temperature and the stage of resuscitation. We limited our study to $4 \mathrm{~h}$ after the time point $\mathrm{T} 2$ because the number of deaths significantly reduced the group, which may have affected the statistical analysis.

Our findings indicate that based on lactate concentration and the value of lactate kinetics, it is possible to identify those patients whose prognosis is worse. A positive value of lactate kinetics may also indicate the coexistence of other factors in addition to hypoperfusion that increase lactate levels. However, considering the current state of knowledge, seeking to lower lactate levels or modifying their kinetics has no credibility [19]. The presented study has several limitations. Foremost, the study was single-center, retrospective in nature and involved a small group of patients. In addition, the study population was not homogeneous regarding the indications for ECLS (hemodynamic instability/cardiac arrest); however, all consecutive patients were analysed. According to the analysed data, cardiac arrest occurred in seven cases $(19.4 \%)$ before the victim was identified. Among the patients with unwitnessed cardiac arrest, three (42\%) survived and four (58\%) died. The uneven distribution of patients to the unwitnessed CA group may carry the potential risk of bias. Similarly, the observed differences between surviving and deceased patients can also result from the witnessed/unwitnessed status of cardiac arrest. The small number of these patients and the relatively high survival rate did not support the subdivision of the study population into three groups.

Detailed v-a ECMO therapy parameters, such as blood flow, fresh gas flow, and rewarming rate, were not recorded. Because of the differences in the initial body core temperature and temperature gradient in individual patients, the time interval between the T1-T2 points was not standardized, and the calculated value of lactate kinetics was not time adjusted.

As we have mentioned, high doses of catecholamines can significantly affect lactate concentrations and thus lactate kinetics. Unfortunately, due to the retrospective nature of our study, we cannot retrieve data determining the precise doses of catecholamines. 
The results of our study allow early selection of patients at high risk of therapy failure. However, further studies are needed to identify alternative therapies in these patients, such as reassigning the rewarming method, modifying the rewarming rate, the early initiation of renal replacement therapy, or using cytokine-absorbing filters.

\title{
5. Conclusions
}

Our results indicate that a high lactate concentration is an independent factor for the poor prognosis of hypothermic patients undergoing ECLS rewarming. Reduced value of lactate kinetics at $4 \mathrm{~h}$ after reaching $30^{\circ} \mathrm{C}$ is also a factor of poor prognosis. Moreover, high potassium levels, persistently low $\mathrm{pH}$ values, $\mathrm{HCO}_{3}$ concentration, and $\mathrm{BE}$ values significantly increase the risk of therapy failure despite the implemented treatment.

\begin{abstract}
Author Contributions: Conceptualization, methodology, formal analysis writing-original draft, project administration, takes responsibility for the paper as a whole: H.H.; methodology, formal analysis, validation, writing - review and editing: P.P., S.K., M.P., K.M., D.H., R.G. and D.P.; methodology, writing-review and editing, supervision: T.D. All authors have read and agreed to the published version of the manuscript.
\end{abstract}

Funding: This article was supported by the science fund of The John Paul II Hospital, Cracow, Poland (no. FN20/2021 to D.P.).

Institutional Review Board Statement: The study was conducted according to the guidelines of the Declaration of Helsinki and approved by the Bioethics Committee of the Jagiellonian University Medical College, Krakow, Poland (no. 1072.6120.344.2018).

Informed Consent Statement: Patient consent was waived due to the retrospective nature of this study.

Data Availability Statement: The data that support the findings of this study are available on request from the corresponding author.

Conflicts of Interest: The authors declare no conflict of interest.

\section{References}

1. Pasquier, M.; Hugli, O.; Paal, P.; Darocha, T.; Blancher, M.; Husby, P.; Silfvast, T.; Carron, P.-N.; Rousson, V. Hypothermia outcome prediction after extracorporeal life support for hypothermic cardiac arrest patients: The HOPE score. Resuscitation 2018, 126, 58-64. [CrossRef]

2. Podsiadło, P.; Darocha, T.; Svendsen, Ø.S.; Kosiński, S.; Silfvast, T.; Blancher, M.; Sawamoto, K.; Pasquier, M. Outcomes of patients suffering unwitnessed hypothermic cardiac arrest rewarmed with extracorporeal life support: A systematic review. Artif. Organs 2021, 45, 222-229. [CrossRef] [PubMed]

3. Lott, C.; Truhlář, A.; Alfonzo, A.; Barelli, A.; González-Salvado, V.; Hinkelbein, J.; Nolan, J.P.; Paal, P.; Perkins, G.D.; Thies, K.-C.; et al. European Resuscitation Council Guidelines 2021: Cardiac arrest in special circumstances. Resuscitation 2021, 161, 152-219. [CrossRef]

4. Cheng, R.; Hachamovitch, R.; Kittleson, M.; Patel, J.; Arabia, F.; Moriguchi, J.; Esmailian, F.; Azarbal, B. Complications of Extracorporeal Membrane Oxygenation for Treatment of Cardiogenic Shock and Cardiac Arrest: A Meta-Analysis of 1,866 Adult Patients. Ann. Thorac. Surg. 2014, 97, 610-616. [CrossRef] [PubMed]

5. Mair, P.; Kornberger, E.; Furtwaengler, W.; Balogh, D.; Antretter, H. Prognostic markers in patients with severe accidental hypothermia and cardiocirculatory arrest. Resuscitation 1994, 27, 47-54. [CrossRef]

6. Darocha, T.; Podsiadło, P.; Polak, M.; Hymczak, H.; Krzych, Ł.; Skalski, J.; Witt-Majchrzak, A.; Nowak, E.; Toczek, K.; Waligórski, S.; et al. Prognostic Factors for Nonasphyxia-Related Cardiac Arrest Patients Undergoing Extracorporeal Rewarming-HELP Registry Study. J. Cardiothorac. Vasc. Anesth. 2020, 34, 365-371. [CrossRef]

7. Podsiadło, P.; Smoleń, A.; Kosiński, S.; Hymczak, H.; Waligórski, S.; Witt-Majchrzak, A.; Drobiński, D.; Nowak, E.; BarteczkoGrajek, B.; Toczek, K.; et al. Impact of rescue collapse on mortality rate in severe accidental hypothermia: A matched-pair analysis. Resuscitation 2021, 164, 108-113. [CrossRef]

8. Mungan, I.; Kazancı, D.; Bektaş, S..; Ademoglu, D.; Turan, S. Does lactate clearance prognosticates outcomes in ECMO therapy: A retrospective observational study. BMC Anesthesiol. 2018, 18, 152. [CrossRef]

9. Haas, S.A.; Lange, T.; Saugel, B.; Petzoldt, M.; Fuhrmann, V.; Metschke, M.; Kluge, S. Severe hyperlactatemia, lactate clearance and mortality in unselected critically ill patients. Intensiv. Care Med. 2016, 42, 202-210. [CrossRef] 
10. Nichol, A.D.; Egi, M.; Pettila, V.; Bellomo, R.; French, C.; Hart, G.; Davies, A.; Stachowski, E.; Reade, M.C.; Bailey, M.; et al. Relative hyperlactatemia and hospital mortality in critically ill patients: A retrospective multi-centre study. Crit. Care 2010, 14, R25. [CrossRef]

11. Vincent, J.-L.; E Silva, A.Q.; Couto, L.; Taccone, F.S. The value of blood lactate kinetics in critically ill patients: A systematic review. Crit. Care 2016, 20, 257. [CrossRef]

12. Sawamoto, K.; Bird, S.B.; Katayama, Y.; Maekawa, K.; Uemura, S.; Tanno, K.; Narimatsu, E. Outcome from severe accidental hypothermia with cardiac arrest resuscitated with extracorporeal cardiopulmonary resuscitation. Am. J. Emerg. Med. 2014, 32, 320-324. [CrossRef]

13. Saczkowski, R.S.; Brown, D.J.; Abu-Laban, R.B.; Fradet, G.; Schulze, C.J.; Kuzak, N.D. Prediction and risk stratification of survival in accidental hypothermia requiring extracorporeal life support: An individual patient data meta-analysis. Resuscitation 2018, 127, 51-57. [CrossRef]

14. Vincent, J.-L.; Dufaye, P.; Berré, J.; Leeman, M.; Degaute, J.-P.; Kahn, R.J. Serial lactate determinations during circulatory shock. Crit. Care Med. 1983, 11, 449-451. [CrossRef] [PubMed]

15. Mizutani, T.; Umemoto, N.; Taniguchi, T.; Ishii, H.; Hiramatsu, Y.; Arata, K.; Takuya, H.; Inoue, S.; Sugiura, T.; Asai, T.; et al. The lactate clearance calculated using serum lactate level $6 \mathrm{~h}$ after is an important prognostic predictor after extracorporeal cardiopulmonary resuscitation: A single-center retrospective observational study. J. Intensiv. Care 2018, 6, 33. [CrossRef]

16. Debaty, G.; Babaz, V.; Durand, M.; Gaide-Chevronnay, L.; Fournel, E.; Blancher, M.; Bouvaist, H.; Chavanon, O.; Maignan, M.; Bouzat, P.; et al. Prognostic factors for extracorporeal cardiopulmonary resuscitation recipients following out-of-hospital refractory cardiac arrest. A systematic review and meta-analysis. Resuscitation 2017, 112, 1-10. [CrossRef]

17. Mégarbane, B.; Deye, N.; Malissin, I.; Baud, F.J. Usefulness of the serum lactate concentration for predicting mortality in acute beta-blocker poisoning. Clin. Toxicol. 2010, 48, 974-978. [CrossRef]

18. Gunnerson, K.J.; Saul, M.; He, S.; Kellum, J.A. Lactate versus non-lactate metabolic acidosis: A retrospective outcome evaluation of critically ill patients. Crit. Care 2006, 10, R22. [CrossRef]

19. Hernandez, G.; Bellomo, R.; Bakker, J. The ten pitfalls of lactate clearance in sepsis. Intensiv. Care Med. 2019, 45, 82-85. [CrossRef] [PubMed]

20. Murray, B.J. Severe lactic acidosis and hypothermia. West. J. Med. 1981, 134, 162-166. [PubMed]

21. Pirnes, J.; Ala-Kokko, T. Accidental hypothermia: Factors related to long-term hospitalization. A retrospective study from northern Finland. Intern. Emerg. Med. 2016, 12, 1225-1233. [CrossRef] [PubMed]

22. Van der Ploeg, G.-J.; Goslings, J.C.; Walpoth, B.H.; Bierens, J.J. Accidental hypothermia: Rewarming treatments, complications and outcomes from one university medical centre. Resuscitation 2010, 81, 1550-1555. [CrossRef]

23. Debaty, G.; Moustapha, I.; Bouzat, P.; Maignan, M.; Blancher, M.; Rallo, A.; Brun, J.; Chavanon, O.; Danel, V.; Carpentier, F.; et al. Outcome after severe accidental hypothermia in the French Alps: A 10-year review. Resuscitation 2015, 93, 118-123. [CrossRef]

24. Okada, Y.; Kiguchi, T.; Irisawa, T.; Yoshiya, K.; Yamada, T.; Hayakawa, K.; Noguchi, K.; Nishimura, T.; Ishibe, T.; Yagi, Y.; et al Predictive accuracy of biomarkers for survival among cardiac arrest patients with hypothermia: A prospective observational cohort study in Japan. Scand. J. Trauma Resusc. Emerg. Med. 2020, 28, 75. [CrossRef]

25. Ahmad, S.; Beckett, M. Recovery from ph 6.38: Lactic acidosis complicated by hypothermia. Emerg. Med. J. 2002, 19, 169-171. [CrossRef]

26. Frei, C.; Darocha, T.; Debaty, G.; Dami, F.; Blancher, M.; Carron, P.; Oddo, M.; Pasquier, M. Clinical characteristics and outcomes of witnessed hypothermic cardiac arrest: A systematic review on rescue collapse. Resuscitation 2019, 137, 41-48. [CrossRef] [PubMed]

27. Soar, J.; Nolan, J.P.; Böttiger, B.W.; Perkins, G.D.; Lott, C.; Carli, P.; Pellis, T.; Sandroni, C.; Skrifvars, M.B.; Smith, G.B.; et al. European Resuscitation Council Guidelines for Resuscitation 2015. Resuscitation 2015, 95, 100-147. [CrossRef]

28. Tveita, T. Pharmacodynamics in hypothermia. Crit. Care 2012, 16, A6. [CrossRef] 